\title{
Exploring the Effect of Gold Support on the Oxygen Reduction Reaction Activity of Metal Porphycenes
}

\author{
Anand, Megha; Siahrostami, Samira; Nørskov, Jens K.
}

\section{Published in:}

ChemCatChem

Link to article, DOI:

$10.1002 /$ cctc. 201801408

Publication date:

2018

Document Version

Peer reviewed version

Link back to DTU Orbit

Citation (APA):

Anand, M., Siahrostami, S., \& Nørskov, J. K. (2018). Exploring the Effect of Gold Support on the Oxygen Reduction Reaction Activity of Metal Porphycenes. ChemCatChem, 10(23), 5505-5510.

https://doi.org/10.1002/cctc.201801408

\section{General rights}

Copyright and moral rights for the publications made accessible in the public portal are retained by the authors and/or other copyright owners and it is a condition of accessing publications that users recognise and abide by the legal requirements associated with these rights.

- Users may download and print one copy of any publication from the public portal for the purpose of private study or research.

- You may not further distribute the material or use it for any profit-making activity or commercial gain

- You may freely distribute the URL identifying the publication in the public portal 


\title{
Exploring the Effect of Gold Support on the Oxygen Reduction Reaction Activity of Metal Porphycenes
}

\author{
Megha Anand, ${ }^{[a, b]}$ Samira Siahrostami, ${ }^{*[a]}$ and Jens K. Nørskov ${ }^{*[a, b, c]}$
}

It has been a long-standing goal to find alternative, cost effective catalysts for oxygen reduction reaction (ORR) in fuel cells. Molecular complexes capable of efficiently catalyzing ORR, when supported on a conducting solid surface could provide interesting hybrid materials combining the best of homogeneous and heterogeneous catalysis. We use density functional theory to study the ORR activity of molecular (unsupported) and gold supported $3 d$ metal (II)-porphycenes (MPc). All the $3 d$ metal-porphycenes adsorb strongly on the $\mathrm{Au}(111)$ support with negative free energy of formation ranging from $1.0-3.0 \mathrm{eV}$ while

\section{Introduction}

Fuel cells have emerged as an attractive technology to generate electricity from the chemical energy of a fuel such as hydrogen, methanol or ethanol. ${ }^{[1]}$ The fuel is oxidized at the anode of the fuel cell to produce protons and electrons which pass through membrane and an external circuit respectively to reduce oxygen at the cathode. The reduction of oxygen to water (known as oxygen reduction reaction, ORR) at the cathode is the bottleneck reaction in the fuel cells. ${ }^{[2]}$ Despite the high cost, scarcity, and low durability, platinum based alloys remain the best known electrocatalysts for ORR in fuel cells. ${ }^{[3]}$ These limitations have prevented the large-scale commercialization of platinum based fuel cells and motivated vast research towards finding alternative non-precious ORR catalysts.

Planar $\mathrm{M}-\mathrm{N}_{4}$ type transition metal complexes, such as ironporphyrins, are well known homogeneous catalysts for ORR which could be used as viable and cheaper alternatives to platinum. ${ }^{[4-16]}$ These catalysts are however dispersed in the homogeneous reaction mixture and therefore it could be challenging to couple them effectively to the electrode surface.

[a] Dr. M. Anand, Dr. S. Siahrostami, Prof. J. K. Nørskov Department of Chemical Engineering

SUNCAT Center for Surface Science and Catalysis

Stanford University

Stanford CA-94035 (USA)

E-mail: samiras@stanford.edu

[b] Dr. M. Anand, Prof. J. K. Nørskov

Department of Physics

Technical University of Denmark

Kongens Lyngby2800 (Denmark)

[c] Prof. J.K. Nørskov

SUNCAT Center for Surface Science and Catalysis

SLAC National Laboratory

Menlo Park CA-94025 (USA)

E-mail: norskov@stanford.edu solvation lowers the energy of molecular MPc by only $0.5 \mathrm{eV}$ compared to the gas phase. These indicate that the $3 d \mathrm{MPc}$ are stable and anchored firmly to the gold surface under ORR conditions. Based on our analysis, the gold support enhances the ORR activity in some of the examined MPc systems. We find that the molecular MnPc and FePc are the best ORR electrocatalysts with theoretical overpotentials of $0.44 \mathrm{~V}$ and $0.36 \mathrm{~V}$. This work highlights the important role of the support in preserving/increasing the activity of molecular catalyst.

One way to circumvent this issue is by fixing molecular catalysts on a conducting solid support. Interestingly, transition metal porphyrins and similar molecular complexes are known to selfassemble on coinage metal supports. ${ }^{[17]}$ Several studies have been devoted towards understanding the molecule-support interaction of transition metal-porphyrins or pthalocyanines on supports such as gold, silver, copper, platinum ${ }^{[18-23]}$ or even non-metal surfaces such as graphene, ${ }^{[24,25]}$ graphene oxide, ${ }^{[26,27]}$ and carbon nanotubes. ${ }^{[23,28,29]}$ Depending on the strength/ nature of the interaction between metal surface and organometallic homogeneous catalyst, the charge, spin, or magnetism of the adsorbed molecular catalyst can be modified which in turn may influence its catalytic properties. ${ }^{[30-32]}$

Fe-Pthalocyanines anchored on $\mathrm{Au}(111)$ via self-assembled monolayers of aromatic thiols and Co-tetraphenylporphyrin on $\mathrm{Au}(111)$ surface revealed improved ORR activity compared to their homogeneous counterparts. ${ }^{[3,34]}$ Graphene supported iron-pthalocyanines have also shown enhanced ORR activity compared to platinum. ${ }^{[35]}$ More recently, a network of covalently connected iron and cobalt-porphyrins embedded around carbon-nanotubes were used as catalysts for the ORR. ${ }^{[10,36]}$ All these findings indicate that the solid support plays an important role towards improving ORR activity of the catalyst. Besides the enhancement in the catalytic activity, selfassembled planar $\mathrm{M}-\mathrm{N}_{4}$ complexes on metal/non-metal supports ensure high and uniform density of well-organized active sites for ORR. ${ }^{[37]}$ Such organometallic/metal interface gives a flexible strategy to combine the high specificity of homogeneous $\mathrm{M}-\mathrm{N}_{4}$ type electrocatalysts with the benefits of heterogeneous catalysis such as easy integrability with the electrode surfaces and/or increasing the catalyst lifetime. ${ }^{[38,39]}$

Herein, we use density functional theory to systematically study the effect of the gold support on the ORR activity of the first row $3 d$ transition metal-porphycenes (MPc). Porphycene (Pc) is a constitutional isomer of porphyrin exhibiting interesting magnetic, optical, electrical and mechanical properties 
similar to porphyrin. ${ }^{[40-42]}$ Metal-porphycenes supported on metal surfaces have attracted much attention in recent years owing to their potential application in designing molecular switches, sensors or photovoltaic devices. ${ }^{[43-45]}$ Here, we focus on the ORR activity of unsupported molecular and gold supported 3d MPc (Figure 1). While the study is done on all 3d metal-porphycenes, we will use FePc to illustrate our key results throughout the manuscript and show that the influence of support is dependent on the central metal (M) in the metalporphycene.

\section{Results and Discussion}

\section{Oxygen Reduction Reaction on Metal-Porphycenes}

We first evaluate the ORR activity of the molecular catalysts. The early $3 d$ MPcs including ScPc, TiPc, and VPc are oxophilic and bind oxygen very strongly. This gives poor ORR catalytic activity since the active site is poisoned by oxygen intermediates. The strong tendency towards oxygen adsorption pulls the metal out of the plane of the ring. As a result, the metalnitrogen linkages are weakened and may even make the ring puckered reducing the catalyst lifetime.

(a) Metal Pophycene (MPc)

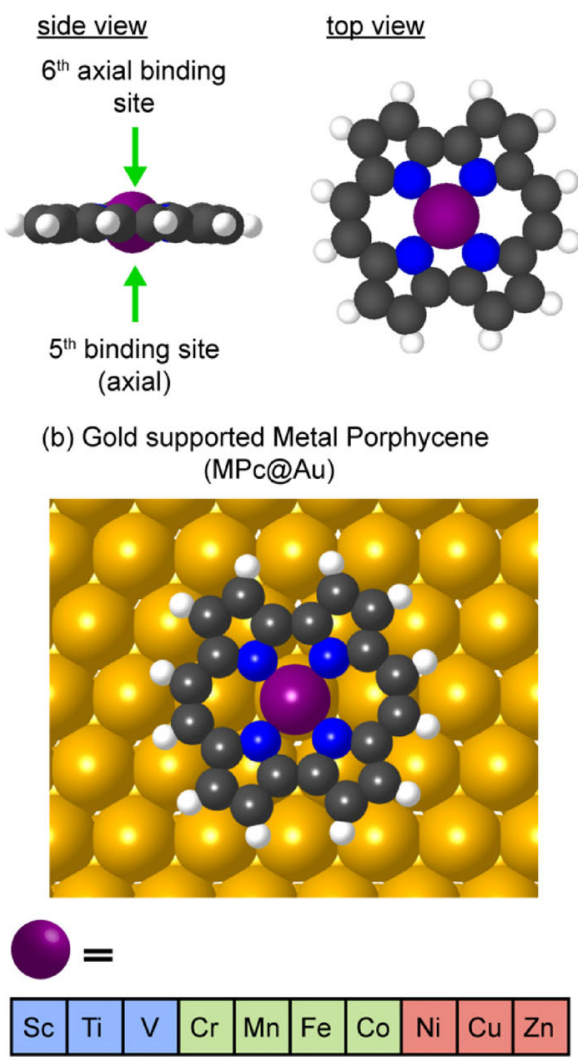

Figure 1. (a) Side and top view of molecular metal porphycene with the illustration of the two binding sites on the molecule. (b) Gold supported first row $3 d$ metal-porphycenes studied for ORR in this work.
Among the central $3 d$ metal-porphycenes i.e., $\mathrm{CrPc}, \mathrm{MnPc}$, FePc, and CoPc the latter two give reasonable ORR activity with overpotentials of $0.66 \mathrm{~V}$ and $0.55 \mathrm{~V}$, respectively (see section S1 in ESI). The theoretical overpotential on $\mathrm{MnPc}$ is $\eta_{\mathrm{MnPc}}=0.85 \mathrm{~V}$ while $\mathrm{CrPc}$ shows negligible or zero activity with high overpotential of $\eta_{\mathrm{crPc}}=1.21 \mathrm{~V}$. The late $3 d \mathrm{MPcs}$ such as NiPc, CuPc and $\mathrm{ZnPc}$ weakly bind ORR intermediates, hence exhibit poor ORR catalytic activity.

Figure 2(a) shows the free energy diagram for ORR on FePc at three different potentials $0,0.63$, and $1.23 \mathrm{~V}$ (blue, red, and black lines) respectively. All the elementary steps of the reaction are spontaneous between $0-0.63 \mathrm{~V}$ where $0.63 \mathrm{~V}$ is the limiting potential. Beyond the limiting potential, the first, third and the fourth thermodynamic steps become uphill. It is worth noting that, since metal-porphycenes have planar structure, the oxygen adsorbates are likely to bind to the $6^{\text {th }}$ axial site on the central metal. We considered all possible combinations of ORR adsorbates at the two axial sites and identified $\mathrm{FePc}-\mathrm{OH}$ as other stable species in the potential range for ORR based on the pourbaix diagrams ( $\Delta G$ versus potential, see section $S 2$ in $\mathrm{ESI}$ ). Figure 2(b) displays the free energy diagrams for ORR on $\mathrm{FePc}$ and $\mathrm{FePc}-\mathrm{OH}$. The theoretical overpotential on FePc-OH is almost half the one of bare FePc. This is because a ligand (or adsorbate) in the $5^{\text {th }}$ coordinating site of $\mathrm{M}-\mathrm{N}_{4}$ type catalysts
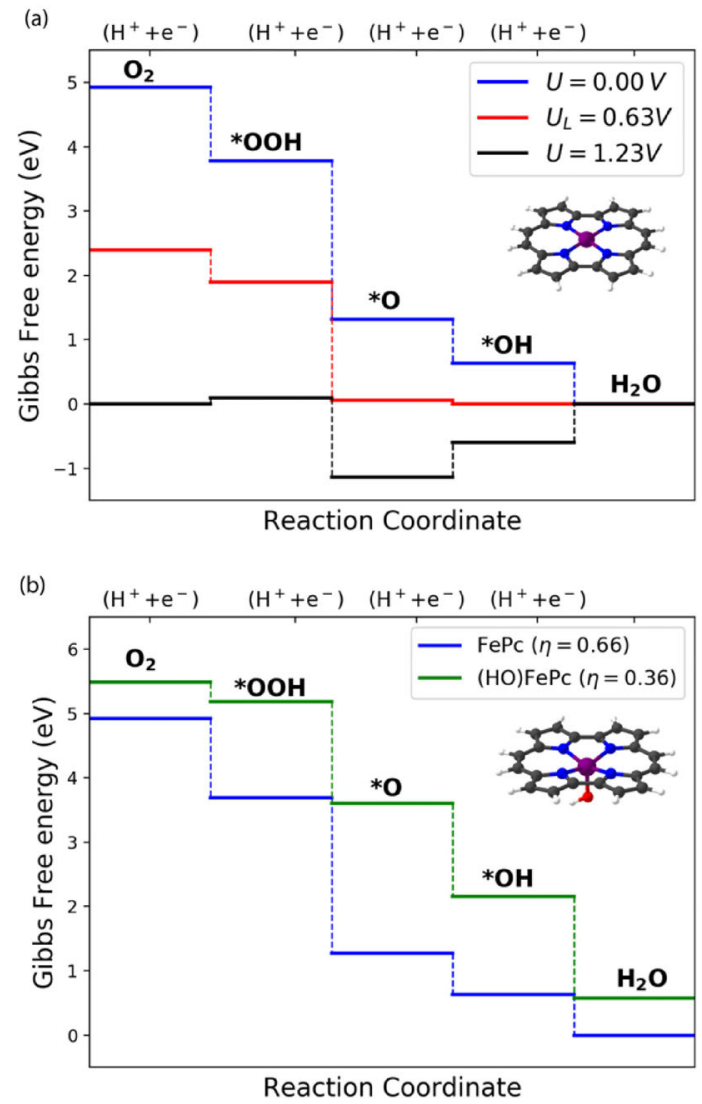

Figure 2. (a) Free energy diagram for ORR using FePc at three different potentials: $0,0.63$ and 1.23 V. (b) Comparative ORR free energy plot of FePc and $\mathrm{FePcOH}$ shown using blue and green color, respectively. 


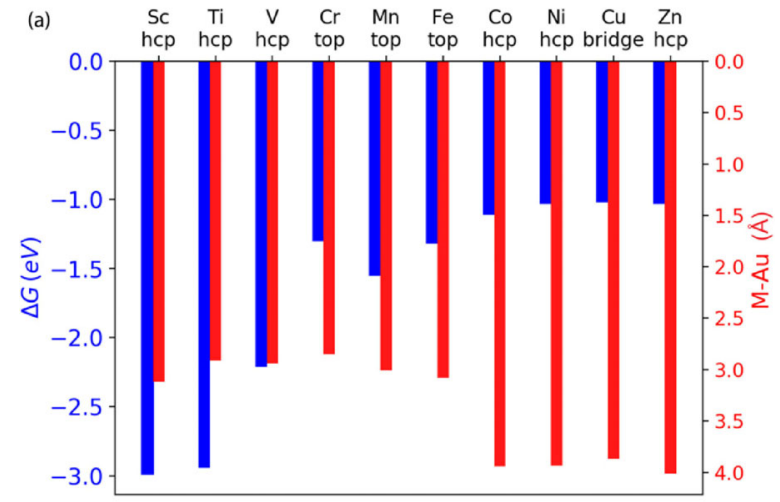

(b)

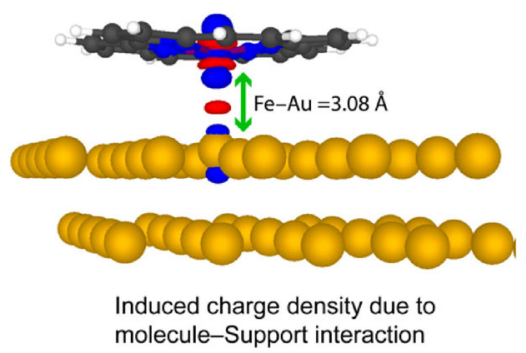

Figure 3. (a) Blue bars are the formation energies $(\Delta E)$ of the hybrid catalyst MPc@Au at the favored site on the gold support. The red bars are the M-Au distance in MPc@Au (on top site). (b) Electron density induced by the interaction of FePc with the $\mathrm{Au}(111)$ support. These iso-surfaces correspond to the value of $\pm 0.003 \mathrm{e} / \AA$ with red and blue representing positive (excess charge) and negative (depleted charge) values respectively.

weakens the binding of all oxygen adsorbates at the sixth axial site. This phenomenon is known as trans-effect where a trans directing ligand lowers the activation barrier of the reaction by either destabilizing the ground state of the complex or by lowering the barrier of the transition state or both. ${ }^{[9,46-48]}$ Similarly, for MnPc the activity is improved $(\eta=0.44 \mathrm{~V})$ when $\mathrm{MnPc}-\mathrm{OH}$ is the active catalyst. Next, we study the ORR activity on the gold supported metal porphycenes.

\section{Oxygen Reduction Reaction on M-Porphycenes Adsorbed on $\mathrm{Au}(111)$ Surface}

To study the effect of the gold support, we first estimated the stability of the hybrid system of first row $3 d$ MPc adsorbed on the $\mathrm{Au}(111)$ support. Only the parallel adsorption of the MPc on the support is considered since the vertical adsorption of $\mathrm{MnPc}$ on $\mathrm{Au}(111)$ has been reported to be energetically unfavorable. ${ }^{[49]}$ Substitued porphyrins may adapt conformations at an angle $\theta$ to the surface depending upon type and strength of the inter-molecular and the molecule-support interactions. ${ }^{[50,51]}$

We first calculate the formation energy $(\Delta G)$ of the hybrid MPc@Au system using the equation: $\Delta G=G_{M-P c @ A u(111)}-\left[G_{M-P c}+\right.$ $\left.G_{A u(111)}\right]$ where $G_{X}$ is the free energy of $X$. The gold support is assumed to be fixed and therefore does not contribute to the entropy and the zero point vibrational energy (See section S3 in ESI for more details). For all the $3 d$ metal-porphycenes, the adsorption of MPc at different sites on the gold surface have comparable formation energies of which the moderately favored ones are shown in the figure 3.

The adsorption of all the MPcs on the Au(111) support have negative free energy of formation with $\Delta G$ smaller than $-1.0 \mathrm{eV}$. This indicates that the molecule-support interaction is more than just the vander waals dispersive interactions especially for the early $3 d$ metal-porphycenes with larger formation energies. The $\mathrm{M}-\mathrm{Au}$ distance is a good indicator of their interaction strength and it decreases as the formation energy increases (Figure 3). ${ }^{[52,53]}$ The $\mathrm{M}-\mathrm{Au}$ distance is even comparable to the $\mathrm{M}-\mathrm{Au}$ distance observed in molecular mixed-metal clusters for some of the MPc@Au systems. For example, the $\mathrm{Fe}-\mathrm{Au}$ distance in known organometallic molecular complexes range from 2.52-3.04 $\AA$ while in FePc@Au, it is $3.08 \AA^{[54]}$

Bader charge analysis shows net charge transfer from the support to the MPc molecule (see section S4 in ESI). Similar charge transfer between $\mathrm{Co}$ and $\mathrm{Mn}$-pthalocyanines and the underlying metallic support has earlier been observed experimentally. ${ }^{[20,29]}$ The difference in electron density due to the molecule-support interaction suggest a surface coordinative bond ${ }^{[55]}$ between the metal in MPc and the gold atom nearest to the metal. It is obtained using Equation [1]:

$\delta \rho=\rho_{\text {total }}-\rho_{\text {support }}-\rho_{\text {molecule }}$

where $\rho_{\text {total }}, \rho_{\text {support }}$ and $\rho_{\text {molecule }}$ are the electron densities of FePc@Au, the Au(111) slab and FePc respectively with FePc and the $A u(111)$ slab geometries exactly the same as in the FePc@Au. We observed that the MPcs with unfilled or half-filled metal $\mathrm{dz}^{2}$ orbitals have stronger interaction with the support. The central metal in the early 3d MPc@Au becomes exoplanar moving closer to the gold support. This is similar to some of the molecular MPc where a strongly bound adsorbate (or ligand) pulls the metal out of the ring. The gold support thus, behaves like a strong ligand with an unusually large cone angle of 180 degrees. We expect the $3 d$ metal-porphycenes to be stable and anchored firmly to the gold surface under the ORR conditions based on the calculated formation energies. In fact, the free energy of solvation of molecular FePc is $-0.5 \mathrm{eV}$ while the formation energy of all MPc@Au is less than $-1.0 \mathrm{eV}$ (Figure 3). Therefore, it is energetically more favorable for the MPc to be adsorbed on the gold support than being dispersed in the solution. To estimate the effect of solvation during the formation of molecule-metal complex, we employed solvation method (VASPsol) as implemented in VASP. ${ }^{[56,57]}$ The solvent stabilizes the binding of FePc on the gold support by $0.14 \mathrm{eV}$ compared to vacuum. Thus, the formation of MPc@Au is energetically favorable and solvation reinforces the adsorption of the molecule on the gold support (see section S5 in ESI for the details on solvation). There are several experimental reports on oxygen reduction reaction using metal-porphyrins adsorbed on gold surface. ${ }^{[34,58]}$ To evaluate the influence of support on ORR activity, we next calculate the binding free energies of ORR intermediates on the hybrid MPc@Au. 


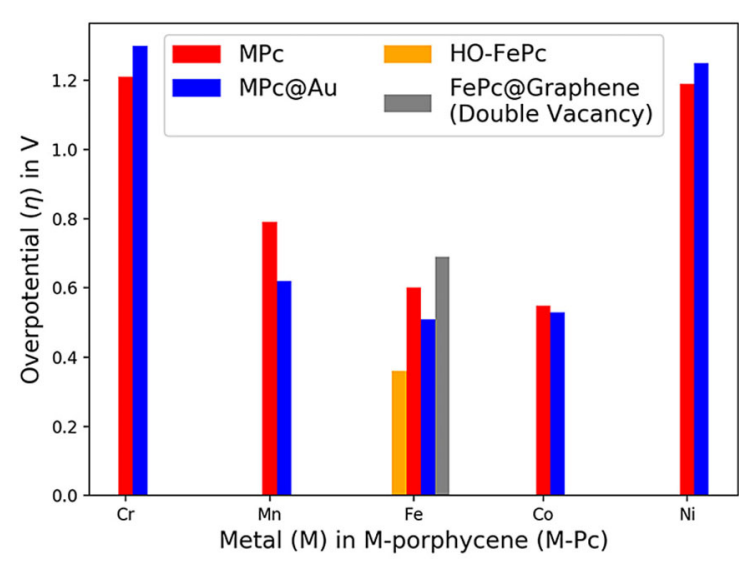

Figure 5. Theoretical ORR overpotential for $\mathrm{O}_{2}$ reduction over several molecular unsupported and gold supported metal-porphycenes.

\section{Binding energies of ORR adsorbates on MPc@Au(111)}

The $\mathrm{OOH}^{*}$ and $\mathrm{OH}^{*}$ binding free energies on molecular and gold-supported MPC fall in the universal scaling of $\Delta \mathrm{G}_{\mathrm{OOH}^{*}}=$ $\Delta \mathrm{G}_{\mathrm{OH}^{*}}+3.2 \mathrm{eV}$ (Figure 4), well established for other catalytic surfaces such as metals, oxides, sulfides, and carbides. ${ }^{[59-61]}$ The ORR adsorbates bind weakly to the central metal in the gold supported ScPc, TiPc, VPc, and $\mathrm{CrPc}$ compared to the unsupported MPc since they experience substantial surfacetrans effect from the gold support (see section S6 in ESI). ${ }^{[62]}$ The binding free energies are almost unchanged by the support for the $\mathrm{CoPc}$, NiPc, CuPc, and $\mathrm{ZnPc}$.

Although the gold support weakens the adsorbate-catalyst interaction on the oxophillic early $3 d$ metal-porphycenes, the binding of adsorbates is still stronger than what is expected for facile ORR. On the other hand, the ORR adsorbates bind too weakly to the gold supported late $3 d \mathrm{MPc}(\mathrm{Ni}, \mathrm{Cu}, \mathrm{Zn})$. The mid$3 d \mathrm{MPc}$ comprising of unsupported and supported MnPc, FePc,

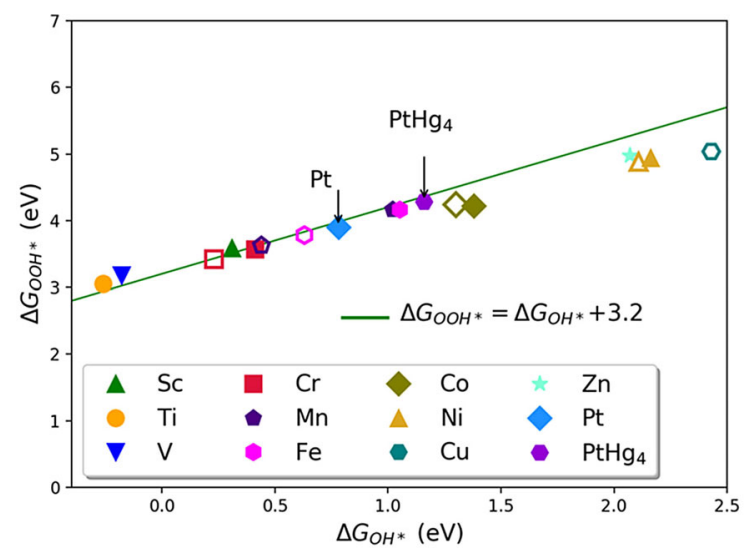

Figure 4. Binding free energies of $\mathrm{OOH}^{*}$ as a function of binding free energy of $\mathrm{OH}^{*}$. The unfilled markers correspond to molecular metal porphycenes. The point not shown in the plot either does not bind $\mathrm{OOH}^{*}$ and $\mathrm{OH}^{*}$ or dissociates into $\mathrm{O}^{*}$ and $\mathrm{OH}$. Pt and $\mathrm{PtHg}_{4}$ data adapted from reference 63. All possible conformations were considered for the $\mathrm{OOH}^{*}$ adsorbate. Only the most favorable one is included in the plot. and $\mathrm{CoPc}$ have the appropriate $\mathrm{OOH}^{*}$ and $\mathrm{OH}^{*}$ binding free energies closer to that of $\mathrm{Pt}$ and thus, are the most promising ORR catalysts of all. ${ }^{[63]}$ These three metal-porphycenes also have slightly lower overpotential comparable to Pt. The gold support reduces the overpotential of $\mathrm{MnPc}, \mathrm{FePc}$, and $\mathrm{CoPc}$ by 0.28 , 0.15 , and $0.02 \mathrm{~V}$ respectively as shown in Figure 5 . The ORR overpotential is slightly improved on $\mathrm{MnPc}$ while remains almost the same for FePc, and CoPc in the presence of the gold support. The strength of the interaction of MPc with the gold support and the adsorbates is dependent on the relative occupancy of $d$-orbitals of the central metal in MPc, particularly the $d z^{2}, d x z$, and $d y z$ orbitals.

\section{Conclusions}

In conclusion, the gold support greatly improves the ORR activity of early $3 d \mathrm{MPc}$ but not to the extent of making its activity comparable to that of gold supported or unsupported FePc and CoPc. The activity is enhanced to a smaller degree for $\mathrm{MnPc}, \mathrm{FePc}$ and $\mathrm{CoPc}$; and almost unaffected for the late $3 d$ $M P c$ in the presence of gold support. We also find that the metal-porphycenes prefer being adsorbed on the gold support rather than being dispersed in solution.

Despite a marginal effect of gold support on the ORR activity of our best molecular electrocatalysts, this work emphasizes the importance of hybrid organic-inorganic system for integrating as efficient ORR catalyst in the cathode of fuel cells. This study directs us to employ other ways to enhance ORR activity of $\mathrm{M}-\mathrm{N}_{4}$ type catalysts such as immobilizing the catalysts on metal (or non-metal) surfaces irreversibly through chemisorption using organic linkers. ${ }^{[58,64-66]}$ A wide variety of organic linkers with heteroatoms such as oxygen, nitrogen, or sulfur can be used since the heteroatoms can coordinate to the iron in FePc as well as the metal atom on the support. Another way to fine-tune the properties of the electrocatalyst is by adding substituents like $-\mathrm{OH},-\mathrm{NH}_{2}$ or $-\mathrm{SH}$ on the organic $\mathrm{N} 4$ ring. Edge-to-edge $\mathrm{H}$-bonding interactions between the electrocatalyst molecules adsorbed on the metal surface can facilitate the in-plane charge transfer. Other supports such as N-doped graphene, or reduced graphene oxide ${ }^{[67]}$ can also influence the ORR activity of molecular catalysts. Recently, $\mathrm{Ni}-\mathrm{O}_{4}$ type organometallic complex on $\mathrm{N}$-doped graphene has been shown to exhibit good ORR activity. ${ }^{[68]}$

\section{Computational Methods}

All computations are performed using the Quantum ESPRESSO program package. ${ }^{[69]}$ Plane wave basis sets with cut-off energy of $475 \mathrm{eV}$ was used. Higher plane wave cut-off energies of 500 and $550 \mathrm{eV}$ give similar result to that of $475 \mathrm{eV}$ (see section S7 in ESI). The atoms are represented using ultra-soft GBRV pseudopotentials. ${ }^{[70]}$ We used BEEF-vdW exchange-correlation functional that has been shown to properly account for such long-range vander waals interactions. ${ }^{[71]}$ We first optimized the bulk properties of the gold and found $a=4.23 \AA$ as the FCC lattice parameter which is in good agreement with the previous experimental and theoretical reports. ${ }^{[72,73]}$ The unit cell consists of one unit of MPc on a 5X5 
$\mathrm{Au}(111)$ surface. To minimize the computational cost, gold slab is represented using two layers of atomic gold where the top layer is allowed to fully relax and the bottom layer is kept fixed at the FCC bulk composition. The calculated adsorption energies remain unchanged when three layers of gold is used as the support (see section S8 in ESI for model computation for FePc) indicating that the third layer of gold atoms has small effect on the catalytic activity of metal-porphycenes. The Brioullin zone was sampled by [4X4X1] k-points using the Monkhorst-Pack scheme for MPc@Au and $\Gamma$-point for the MPc. Sufficient vacuum of approximately $15 \AA$ was included in the $z$-direction to avoid interaction between slabs. All the structures were allowed to relax until the forces converged below $0.05 \mathrm{eV}$. All energies are reported in electron volts $(\mathrm{eV})$ and computations are done spin polarized. We performed test computations on molecular iron-porphycenes using Gaussian 16 that uses atom-centered basis sets. ${ }^{[74]}$ The computed binding free energies of ORR adsorbates are comparable to the BEEF-vdW free energies obtained using Quantum ESPRESSO. See section S9 in ESI for more details. The solvation energy of molecular FePc is evaluated using Truhlar's SMD implicit solvation model implemented in Gaussian 16. ${ }^{[75]}$ We have studied the associative mechanism for ORR which involves three key intermediates $-\mathrm{OOH}^{*}$, $\mathrm{O}^{*}$, and $\mathrm{OH}^{*}$ (where ${ }^{*}$ refers to the catalyst) formed via coupled proton-electron transfer mechanism as shown in Scheme $1 .{ }^{[7]}$

$$
\begin{array}{rll}
\mathrm{O}_{2}+\left(\mathrm{H}^{+}+\mathrm{e}^{-}\right) \stackrel{\Delta \mathrm{G}_{1}}{\longrightarrow} \mathrm{OOH}^{*} & \Delta \mathrm{G}_{1}=\Delta \mathrm{G}_{\mathrm{OOH}^{*}} \\
\mathrm{OOH}^{*}+\left(\mathrm{H}^{+}+\mathrm{e}^{-}\right) \stackrel{\Delta \mathrm{G}_{2}}{\longrightarrow} \mathrm{O}^{*}+\mathrm{H}_{2} \mathrm{O} & \Delta \mathrm{G}_{2}=\Delta \mathrm{G}_{\mathrm{O}^{*}-\Delta \mathrm{OOH}^{*}} \\
\mathrm{O}^{*}+\left(\mathrm{H}^{+}+\mathrm{e}^{-}\right) \stackrel{\Delta \mathrm{G}_{3}}{\longrightarrow} \mathrm{OH}^{*} & \Delta \mathrm{G}_{3}=\Delta \mathrm{G}_{\mathrm{OH}^{*}}-\Delta \mathrm{G}^{*} \\
\mathrm{OH}^{*}+\left(\mathrm{H}^{+}+\mathrm{e}^{-}\right) \stackrel{\Delta \mathrm{G}_{4}}{\longrightarrow} \mathrm{H}_{2} \mathrm{O} & \Delta \mathrm{G}_{4}=4.92-\Delta \mathrm{G}_{\mathrm{OH}^{*}}
\end{array}
$$

Scheme 1. Associative mechanism for oxygen reduction reaction.

We used the computational hydrogen electrode (CHE) model which exploits the fact that the energy of proton-electron pair $(\mathrm{H}++\mathrm{e}-)$ is equivalent to half the energy of molecular hydrogen in gas phase at $\mathrm{U}=0$ versus relative hydrogen electrode RHE. ${ }^{[76]}$ The binding free energies, $\Delta G_{X}$ (for $\mathrm{X}=\mathrm{OOH}^{*}, \mathrm{O}^{*}, \mathrm{OH}^{*}$ ) of the adsorbates are calculated using the equation: $\Delta G_{X}=\Delta E_{X}+\left(\Delta Z P E_{X} T \Delta S_{X}\right)$ where $\Delta E$ is the difference in electronic energy of the adsorbate $X$ with respect to the bare catalyst, $\mathrm{H}_{2}(\mathrm{~g})$ and $\mathrm{H}_{2} \mathrm{O}(\mathrm{g}), \Delta Z \mathrm{PE}_{\mathrm{X}}$ is the difference in zero-point energies, and $\Delta S$ is the change in entropy. The $\left(\Delta Z P E_{X}-T \Delta S_{X}\right)$ values are taken from the earlier paper. ${ }^{[76]}$ The effect of potential on $\Delta G_{x}$ is taken into account by changing the energy of an electron by $-\mathrm{eU}$ units. We measure the activity of an electrocatalyst in terms of limiting potential $\left(U_{L}\right)$ which is defined as the maximum potential at which all the reaction steps are downhill in free energy. The theoretical overpotential $(\eta)$ is defined as the difference between limiting potential and equilibrium potential $(1.23 \mathrm{~V})$. An ideal ORR catalyst, if existed, would have zero overpotential at $1.23 \mathrm{~V}$. It has been shown that the theoretical overpotential is a good descriptor of ORR activity. ${ }^{[7]}$

\section{Acknowledgements}

We gratefully acknowledge Dr. Seoin Back from Stanford University for performing the VASPSol computations. This work has been generously funded by Toyota Research Institute.

\section{Conflict of Interest}

The authors declare no conflict of interest.

Keywords: heterogeneous catalysis - homogeneous catalysis • metal-porphycenes . oxygen reduction reaction . electrocatalysis

[1] S. Srinivasan, Fuel cells: from fundamentals to applications, Springer Science \& Business media, New York, 2006, pp. 189-222.

[2] A. Wieckowski, in Fuel cell catalysis: a surface science approach (Eds.: M. Koper), vol. 1, John Wiley \& Sons, Inc., Hoboken, New Jersey, 2009, pp. $1-30$.

[3] J. Zhang, PEM fuel cell electrocatalysts and catalyst layers: fundamentals and applications, Springer Science \& Business Media, London, 2008, pp. 631-654.

[4] C. W. B. Bezerra, L. Zhang, K. Lee, H. Liu, A. L. B. Marques, E. P. Marques, H. Wang, J. Zhang, Electrochim. Acta 2008, 53, 4937-4951.

[5] E. I. Solomon, S. Goudarzi, K. D. Sutherlin, Biochemistry 2016, 55, 63636374.

[6] G. Wu, K. L. More, C. M. Johnston, P. Zelenay, Science 2011, 332, 443448.

[7] C. H. Choi, W. S. Choi, O. Kasian, A. K. Mechler, M. T. Sougrati, S. Brüller, K. Strickland, Q. Jia, S. Mukerjee, K. J. Mayrhofer, F. Jaouen, Angew. Chem. Int. Ed. 2017, 8809-8812.

[8] X. Chen, R. Hu, F. Bai, Materials 2017, 10, 549.

[9] T. Ohta, P. Nagaraju, J. G. Liu, T. Ogura, Y. Naruta, J. Biol. Inorg. Chem. 2016, 21, 745-755.

[10] H. Jia, Z. Sun, D. Jiang, S. Yang, P. Du, Inorg. Chem. Front. 2016, 3, 821827.

[11] U. Tylus, Q. Jia, K. Strickland, N. Ramaswamy, A. Serov, P. Atanassov, S. Mukerjee, J. Phys. Chem. C 2014, 118, 8999-9008.

[12] M. Jahan, Q. Bao, K. P. Loh, J. Am. Chem. Soc. 2012, 134, 6707-6713.

[13] J. H. Zagal, M. T. Koper, Angew. Chem. Int. Ed. 2016, 55, 14510-14521; Angew. Chem. 2016, 128, 14726-14738.

[14] M. Lefevre, E. Proietti, F. Jaouen, J. P. Dodelet, Science 2009, 324, 71-74.

[15] S. Dey, B. Mondal, S. Chatterjee, A. Rana, S. Amanullah, A. Dey, Nat. Rev. 2017, 1, 1-20.

[16] K. Singh, F. Razmjooei, J. S. Yu, J. Mater. Chem. A 2017, 5, 20095-20119.

[17] L. Dong, Z. Gao, N. Lin, Prog. Surf. Sci. 2016, 91, 101-135.

[18] A. Bhattarai, U. Mazur, K. W. Hipps, J. Am. Chem. Soc. 2014, 136, 21422148.

[19] W. Auwärter, A. Weber-Bargioni, A. Riemann, A. Schiffrin, O. Gröning, R. Fasel, J. V. Barth, J. Chem. Phys. 2006, 124, 194708-194714.

[20] F. Petraki, H. Peisert, F. Latteyer, U. Aygul, A. Vollmer, T. Chass, J. Phys. Chem. C 2011, 115, 21334-21340.

[21] J. M. Gottfried, Surf. Sci. Rep. 2015, 70, 259-379.

[22] D. P. Miller, J. Hooper, S. Simpson, P. S. Costa, N. Tyminka, S. M. Mcdonnell, J. A. Bennett, A. Enders, E. Zurek, J. Phys. Chem. C 2016, 120, 29173-29181.

[23] W. Auwärter, D. Écija, F. Klappenberger, J. V. Barth, Nat. Chem. 2015, 7, 105-120.

[24] T. Xue, S. Jiang, Y. Qu, Q. Su, R. Cheng, S. Dubin, C. Y. Chiu, R. Kaner, Y. Huang, X. Duan, Angew. Chem. Int. Ed. 2012, 51, 3822-3825; Angew. Chem. 2012, 124, 3888-3891.

[25] F. Tasca, F. J. Recio, R. Venegas, D. A. Geraldo, M. Sancy, J. H. Zagal, Electrochim. Acta 2014, 140, 320-331.

[26] H. Yin, C. Zhang, F. Liu, Y. Hou, Adv. Funct. Mater. 2014, 24, 2930-2937.

[27] I. S. Hosu, Q. Wang, A. Vasilescu, S. F. Peteu, V. Raditoiu, S. Railian, V. Zaitsev, K. Turcheniuk, Q. Wang, M. Li, R. Boukherroub, S. Szunerits, RSC Adv. 2015, 5, 1474-1484

[28] L. Alvarez, F. Fall, A. Belhboub, R. L. Parc, Y. Almadori, R. Arenal, R. Aznar, P. DieudonneGeorge, P. Hermet, A. Rahmani, B. Jousselme, S. Campidelli, J. Cambedouzou, T. Saito, J. L. Bantignies, J. Phys. Chem. C 2015, 119, 5203-5210.

[29] J. Uihlein, M. Polek, M. Glaser, H. Adler, R. Ovsyannikov, M. Bauer, M. Ivanovic, A. B. Preobrajenski, A. V. Generalov, T. Chasse, H. Peisert, J. Phys. Chem. C 2015, 119, 15240-15247.

[30] I. O. Benítez, B. Bujoli, L. J. Camus, C. M. Lee, F. Odobel, D. R. Talham, J. 
[31] M. Fanetti, A. Calzolari, P. Vilmercati, C. CastellarinCudia, P. Borghetti, G. D. Santo, L. Floreano, A. Verdini, A. Cossaro, I. Vobornik, E. Annese, F. Bondino, S. Fabris, A. Goldoni, J. Phys. Chem. C 2011, 115, 11560-11568.

[32] S. S. Akimenko, V. A. Gorbunov, A. V. Myshlyavtsev, Procedia Eng. 2015, 113, 108-112.

[33] I. Ponce, J. F. Silva, R. O. Oñate, M. C. Rezende, M. A. Paez, J. Zagal, J. Pavez, F. Mendizabal, S. Miranda-Rojas, A. M. Muñoz Castro, R. ArratiaPerez, J. Phys. Chem. C 2012, 116, 15329-15341.

[34] S. Yoshimoto, A. Tada, K. Suto, R. Narita, K. Itaya, Langmuir 2003, 19, 672-677.

[35] Y. Jiang, Y. Lu, X. Lv, D. Han, Q. Zhang, L. Niu, W. Chen, J. Am. Chem. Soc. 2013, 3, 1263-1271.

[36] I. Hijazi, T. Bourgeteau, R. Cornut, A. Morozan, A. Filoramo, J. Leroy, V. Derycke, B. Jousselme, S. Campidelli, J. Am. Chem. Soc. 2014, 136, 63486354.

[37] R. Cao, A. M. Díaz-García, R. Cao, Coord. Chem. Rev. 2009, 253, 12621275.

[38] R. Ye, T. J. Hurlburt, K. Sabyrov, S. Alayoglu, G. A. Somorjai, Proc. Natl. Acad. Sci. India 2016, 113, 5159-5166.

[39] C. Copéret, A. Fedorov, P. A. Zhizhko, Catal. Lett. 2017, 147, 2247-2259.

[40] E. Vogel, M. Kocher, H. Schmickler, J. Lex, Angew. Chem. Int. Ed. Engl. 1986, 25, 257-259.

[41] G. Anguera, D. Sachez-García, Chem. Rev. 2017, 117, 2481-2516.

[42] J. Waluk, Chem. Rev. 2017, 117, 2447-2480.

[43] T. Kumagai, F. Hanke, S. Gawinkowski, J. Sharp, K. Kotsis, J. Waluk, M. Persson, L. Grill, Phys. Rev. Lett. 2013, 111, 9-13.

[44] T. Kumagai, F. Hanke, S. Gawinkowski, J. Sharp, K. Kotsis, J. Waluk, M. Persson, L. Grill, Nat. Chem. 2014, 6, 41-46.

[45] S. Yoshimoto, T. Kawamoto, T. Okawara, Y. Hisaeda, M. Abe, Langmuir 2016, 32, 13635-13639.

[46] S. S. Zumdahl, R. S. Drago, J. Am. Chem. Soc. 1968, 90, 6669-6675

[47] R. Cao, R. Thapa, H. Kim, X. Xu, M. G. Kim, Q. Li, N. Park, M. Liu, J. Cho, Nat. Commun. 2013, 4, 1-7.

[48] J. Chlistunoff, J. -M. J. Sansiñ, J. Phys. Chem. C 2014, 118, 19139-19149.

[49] K. Leung, S. B. Rempe, P. A. Schultz, E. M. Sproviero, V. S. Batista, M. E. Chandross, C. J. Medforth, J. Am. Chem. Soc. 2006, 128, 3659-3668.

[50] P. Donovan, A. Robin, M. S. Dyer, M. Persson, R. Raval, Chem. Eur. J. 2010, 16, 11641-11652.

[51] G. Di Santo, C. Castellarin-Cudia, M. Fanetti, B. Taleatu, P. Borghetti, L. Sangaletti, L. Floreano, E. Magnano, F. Bondino, A. Goldoni, J. Phys. Chem. C 2011, 115, 4155-4162.

[52] B. Stadtmüller, S. Schröder, C. Kumpf, J. Electron Spectrosc. Relat. Phenom. 2015, 204, 80-91.

[53] S. Duhm, A. Gerlach, I. Salzmann, B. Bröker, R. L. Johnson, F. Schreiber, N. Koch, Org. Electron. 2008, 9, 111-118.

[54] P. Braunstein, J. Rose, Gold Bull. 1985, 18, 17-30.

[55] C. Wäckerlin, D. Chylarecka, A. Kleibert, K. Müller, C. lacovita, F. Nolting, T. A. Jung, N. Ballav, Nat. Commun. 2010, 61, 1-7.

[56] K. Mathew, R. Sundararaman, K. Letchworth-Weaver, T. A. Arias, R. G. Henning, J. Chem. Phys. 2014, 140, 084106.

[57] G. Kresse, D. Joubert, Phys. Rev. B 1999, 59, 1758-1775.

[58] X. Lu, B. Lv, Z. Xue, M. Li, L. Zhang, J. Kang, Thin Solid Films 2005, 488, 230-235.
[59] J. K. Nørskov, F. Studt, F. Abild-Pedersen, T. Bligaard, Energy Trends in Catalysis in Fundamental Concepts in Heterogeneous Catalysis, John Wiley \& Sons, Inc, Hoboken, New Jersey, 2014, pp. 85-96.

[60] I. C. Man, H. Y. Su, F. Calle-Vallejo, H. A. Hansen, J. I. Martínez, N. G. Inoglu, J. Kitchin, T. F. Jaramillo, J. K. Nørskov, J. Rossmeisl, ChemCatChem 2011, 3, 1159-1165.

[61] S. Siahrostami, C. Tsai, M. Karamad, R. Koitz, M. García-Melchor, M. Bajdich, A. Vojvodic, F. Abild-Pedersen, J. K. Nørskov, F. Studt, Catal. Lett. 2016, 146, 1917-1921.

[62] W. Hieringer, K. Flechtner, A. Kretschmann, K. Seufert, W. Auwarter, J. V. Barth, A. Gorling, H. P. Steinruck, J. M. Gottfried, J. Am. Chem. Soc. 2011, 133, 6206-6222.

[63] S. Siahrostami, A. Verdaguer-Casadevall, M. Karamad, D. Deiana, P. Malacrida, B. Wickman, M. Escudero-Escribano, E. A. Paoli, R. Frydendal, T. W. Hansen, I. Chorkendorff, I.E. L. Stephens, J. Rossmeisl, Nat. Mater. 2013, 12, 1137-1143.

[64] J. E. Hutchison, T. A. Postlethwaite, R. W. Murray, Langmuir 1993, 9, 3211-3283.

[65] S. Yoshimoto, J. Inukai, A. Tada, T. Abe, T. Morimoto, A. Osuka, H. Furuta, K. Itaya, J. Phys. Chem. B 2004, 108 (6), 1948-1954.

[66] M. E. Ragoussi, G. Katsukis, A. Roth, J. Malig, G. D. L. Torre, D. M. Guldi, T. Torres, J. Am. Chem. Soc. 2014, 136, 4593-4598.

[67] H. Tang, H. Yin, J. Wang, N. Yang, D. Wang, Z. Tang, Angew. Chem. Int. Ed. 2013, 52, 5585-5589; Angew. Chem. 2013, 125, 5695-5699.

[68] D. Jang, S. Lee, Y. Shin, S. Ohn, S. Park, D. Lim, G. Park, S. Park, Solid State Sci. 2017, 74, 56-61.

[69] G. Paolo, B. Stefano, B. Nicola, C. Matteo, C. Roberto, C. Carlo, C. Davide, L. C. Guido, C. Matteo, D. Ismaila, D. C. Andrea, de Gironcoli Stefano, F. Stefano, F. Guido, G. Ralph, G. Uwe, G. Christos, K. Anton, L. Michele, M. S. Layla, M. Nicola, M. Francesco, M. Riccardo, P. Stefano, P. Alfredo, P. Lorenzo, S. Carlo, S. Sandro, S. Gabriele, P. S. Ari, S. Alexander, U. Paolo, M. W Renata, J. Phys. Condens. Matter 2009, 21395502 (19pp).

[70] K. F. Garrity, J. W. Bennett, K. M. Rabe, D. Vanderbilt, Comp. Mat. Sci. 2014, 81, 446-452.

[71] J. Wellendorff, K. T. Lundgaard, A. Møgelhøj, V. Petzold, D. D. Landis, J. K. Nørskov, T. Bligaard, K. W. Jacobsen, Phys. Rev. B 2012, 85, 235149235170.

[72] W. P. Davey, Phys. Rev. 1925, 25, 753.

[73] R. L. Arevalo, S. M. Aspera, H. Nakanishi, H. Kasai, S. Yamaguchi, K. Asazawa, Catal. Lett. 2018, 148, 1073-1079.

[74] M. J. Frisch, Gaussian 16 Revision B.01. 2016; 2016 Gaussian Inc. Wallingford CT.

[75] A. V. Marenich, C. J. Cramer, D. G. Truhlar, J. Phys. Chem. B 2009, 113, 6378-6396.

[76] J. K. Nørskov, J. Rossmeisl, A. Logadottir, L. Lindqvist, J. R. Kitchin, T. Bligaard, H. Jónsson, J. Phys. Chem. B 2004, 108, 17886-17892.

[77] A. Kulkarni, S. Siahrostami, A. Patel, J. K. Nørskov, Chem. Rev. 2018, 118, 2302-2312.

Manuscript received: August 29, 2018

Version of record online: November 13, 2018 